\title{
LA DIFÍCIL DISTINCIÓN ENTRE HUMANOS Y ANIMALES*
}

\author{
Hernán Neira \\ Universidad de Santiago de Chile \\ www.neira.cl
}

\begin{abstract}
RESUMEN / ABSTRACT
El concepto "animal" no suele ser dilucidado, es decir, cómo y por qué podemos hablar de algo así como "animales". En el camino de comprender cómo llegan los animales humanos a distinguirse de otros animales hemos examinado la propuesta de Bimbenet, Heidegger, de Rousseau y la de Lévi-Strauss, así como otras propuestas de antropología empírica, como las de Washburn y Moore y la de Lee Berger. Es necesario decidir filosóficamente si lo que se distingue es un hecho o un criterio puesto por el investigador.

Palabras ClaVE: zoofilosofía, diferencia antropológica, epistemología de los animales, relación con los animales, evolución.
\end{abstract}

\section{THE DIFFICULT DISTINCTION BETWEEN HUMANS AND ANIMAL}

The concept "animal" is not frequently analysed, neither the fact of how we can speak about something as "animals". On the road leading to come to understanding of how human beings distinguish themselves from other animals, we have examined the proposals of Bimbenet, Heidegger, Rousseau and Lévi-Strauss as well as those of the empirical anthropologists Washburn and Moore, and the one of Lee Berger. It is necessary to decide whether what is distinguished is a fact or a criteria settled by the researcher.

Keywords: Zoo philosophy, anthropological difference, animal epistemology, relations with animals, evolution.

RA Muy lejos de ser una moda contemporánea, la literatura filosófica sobre los animales es tan antigua y amplia como la filosofía misma (Fontenay 1998), trabajo en el que muchas veces se discute sobre las características de los animales con la finalidad de proponer algo que los distinga de los humanos. Este aspecto, y otros, han sido examinados por numerosos autores. Así, por ejemplo: las características vitales de los animales fueron analizadas por Aristóteles (On the soul y Parvia Naturalia, 1957); su supuesta (in)capacidad sensible recibió la atención de Descartes (Méditations sur la philosophie première, 2012 [1641]); su capacidad de aprendizaje ocupó un trabajo

Fruto parcial de la investigación Humanos, sub humanos, animales: los límites de la humanidad (1120730), financiada por el Fondo Nacional de Investigación, Ciencia y Tecnología, República de Chile. 
entero de Condillac (Traité des animaux, 2012 [1755]); Heidegger estudió el tipo de existencia animal (Grundbegriffe der Metaphysik, 1992 [1930], así como también lo hizo, en tiempos más cercanos, Florence Burgat (Une autre existence, 2012); los derechos de los animales han sido tratados por Singer (Animal liberation, 1991) y por Tom Regan (The case for animal rights, 1983); la historicidad de la diferencia fue tema de Agamben (Lo abierto, 2006); a la duda sobre lo que es la animalidad y la humanidad dedicó Derrida uno de sus últimos trabajos (L'animal que donc je suis, 2006); Bimbenet vuelve sobre nuevas bases sobre la diferencia antropológica (Bimbenet 2011); Gaffoglio se ha ocupado del resquebrajamiento de lo humano y de lo animal en el campo jurídico (2014); y los criterios de relación jurídico-política entre humanos y animales fueron tratados recientemente por Donaldson y Kymlicka (Zoopolis, 2011) ${ }^{1}$.

La zoofilosofía, por tanto, está bien asentada en la tradición filosófica. La reciente multiplicación de trabajos filosóficos sobre los animales no corresponde, en consecuencia, tanto a una novedad temática, como al hecho de que en las últimas décadas este tema ha tomado conciencia de sí en la filosofía, reclasificando en un mismo tema-zoofilosofía- discusiones que previamente fueran asignadas a otros campos disciplinarios o sub-disciplinarios. Los mencionados autores aceptan la existencia de diferencias entre humanos y animales, unos de manera gradual, a veces poco perceptibles, otros como características completamente distintas y sin continuidad. Ahora bien, el hecho epistemológico del nacimiento de lo animal como campo conceptual no siempre es dilucidado; no se dilucida cómo y por qué podemos hablar de algo así como "animales", lo que deja también bajo cierta oscuridad el tipo de vínculo que mantienen o deben mantener los animales humanos con los animales no humanos. Por eso, entre las posibilidades de la zoofilosofía que hemos nombrado precedentemente queremos centrarnos en la distinción o semejanza entre animales y humanos. Aristóteles, Descartes o incluso Heidegger suelen fundar esa distinción en la observación, empírica o fenomenológica, con o sin reducción o epoké, de ciertos rasgos morfológicos, de comportamiento, de capacidad de conocimiento o existenciales, dando prioridad a cuál es la diferencia antropológica sobre el cómo se constituye. En otras palabras, independientemente de que se niegue o afirme la proximidad entre humanos y animales falta aún la pregunta y más aún la respuesta a esto: ¿puede resolverse la o las diferencias antropológicas respecto de los demás animales por observación o más bien la observación está determinada por una decisión epistemológica que permite crear el campo conceptual de lo humano y de lo animal para ver después qué especies pueden ser incluidas en el primero o en el segundo? Introducir esta pregunta en la zoofilofía o en las zoofilosofías supone complementarlas con un nuevo campo temático. Si respondemos afirmativamente a ella, si la diferencia antropolófica (o zoológica) tiene un origen epistemológico antes que empírico, la consecuencia inmediata sería constatar que los intentos por hallar esa diferencia desde el punto de vista empírico adolecerían de cierta desorientación inicial y que los debates ético-políticos en relación con los animales cambiarían de perspectiva, debiendo también ser replanteados. Lo anterior 
no quiere decir que no se deba tomar en cuenta el conocimiento existencial o empírico para analizar la diferencia antropológica, sino el hecho de que esa vía puede describir diferencias, pero no fundarlas, y que algunas pretensiones de hacerlo no son admisibles. Llevar adelante esta tarea de manera exhaustiva es un trabajo que sobrepasa nuestras posibilidades, motivo por el que en este momento hemos preferido centrarnos en las posibilidades y dificultades de dicho tema revisando algunos hitos de la investigación empírica y de la filosofía. En este último campo, nos hemos centrado en L'animal que donc je ne suis plus, de Etienne Bimbenet (E. Bimbenet 2011), al que interrogamos desde dos autores clásicos: Rousseau y Lévi-Strauss. Para ello partiremos con una breve reflexión sobre Heidegger.

Al tratar el tema de lo que él llama pobreza de mundo de los animales, por oposición a la riqueza de mundo que significaría que los humanos sean creadores de él, Heidegger no logra superar ni la metafísica que critica ni tampoco fundar una diferencia entre lo animal y lo humano. Subsisten en la propuesta heideggeriana al menos dos aspectos no explicados. Recuérdese que Heidegger apoya la idea de que los animales se diferencian de los humanos por el hecho de que los primeros tienen "menos" mundo, menos como opuesto a riqueza (Reichtum); la pobreza (Armut) es menos frente a lo más (284), pues el mundo de los animales estaría restringido a determinado ámbito, lo que incluye una restricción o pobreza de la penetrabilidad de lo que es accesible (zugänglich). Por eso, la abeja no conoce los pistilos en tanto pistilos ("sie kennt nicht die Staubgefäße dieser Blüten als Staubgefäße”) (Heidegger 1992, § 46, p. 285). Ahora bien, nada empírico ni fenomenológico explica tal afirmación. Y, el segundo aspecto no explicado por él es que no da fundamento para colocar como criterio de distinción entre humanos y animales la capacidad de conocer algo "en tanto tal". En realidad, el criterio de conocimiento "en tanto tal" solo rige a partir de la pretensión previa que la tradición metafísica hace de un tipo de conocimiento - en conocimiento en tanto talque la humanidad tiene del pistilo una característica válida para establecer la diferencia entre humanos y animales. Es altamente probable -quizás no se pueda estar cierto-que algunos animales no tengan ese conocimiento, pero en sentido estricto quizás tampoco lo tengan algunos humanos, como lo planteó Diógenes de Sínope, quien incluso habría insinuado que tal tipo de conocimiento no se da. Así está narrada la anécdota y la mofa de Diógenes relativa a ello:

Disputando Platón acerca de las ideas, y usando de las voces mesalidad y vaseidad, [Diógenes de Sínope] dijo: "Yo, oh Platón, veo la mesa y el vaso; pero no la mesalidad ni la vaseidad". A esto respondió Platón: "Dices bien; pues tienes ojos con que se ven el vaso y la mesa, pero no tienes mente con que se entiende la mesalidad y vaseidad" (Laercio 1999, §24).

Un cuestionamiento relativamente elemental como el que hace Diógenes de Sínope a la metafísica platónica, fundamento de la historia posterior de esta disciplina, amenaza o incluso echa por tierra la posibilidad del conocimiento de algo "en tanto tal", que es como si un conocimiento fuese posible privado de todo sujeto de conocimiento, y también cuestiona el privilegio que algunos humanos tendrían de alcanzar dicho conocimiento. Naturalmente, la abeja no conoce el pistilo en tanto tal, sino en tanto 
ella se relaciona con él. Con la afirmación heideggeriana de que la abeja no conoce el pistilo en tanto tal es fácil concordar. Así también se puede concordar con Heidegger en que la comprensión de lo animal y de la vida no es ni puede ser empírica (Heidegger, $\S 45)$. Es decir, Heidegger comprende el hecho de que la vida no es algo que pueda ser decidido a partir de un estudio de laboratorio o de observación zoológica. Ahora bien, a la hora de distinguir a los animales de los humanos, Heidegger -alejándose de su misma vocación y planteamiento- distingue la abeja del Dasein por una accesibilidad al mundo apoyada en características perceptivas: una diferencia en la capacidad cognoscitiva entre animales y humanos en relación con el pistilo. Que una abeja no conozca el pistilo en cuanto tal es una observación zoológica, no un supuesto epistemológico, ni tampoco metafísico, pero, al sostenerlo, como lo hace, restablece el insuficientemente fundado primado de lo humano proveniente de una historia de la metafísica que él busca cuestionar: su afirmación relativa al conocimiento "en tanto tal" solo es válida al interior de esta tradición. Esa tradición fue puesta en tela de juicio por Diógenes de Sínope al referirse a la vaseidad.

Es altamente probable que detrás de la afirmación heideggeriana sobre el pistilo y la abeja esté la hipótesis de Umwelt o medio ambiente, que hereda de von Uexküll. Esta noción es radicalmente distinta de lo que se entiende hoy por dicho concepto. La hipótesis de Umwelt propuesta por von Uexküll y heredada por Heidegger no supone coevolución y fue construida como un instrumento antievolucionista. Su propósito es probar que la especie y el entorno son fijos, dándose una armonía y calce perfecto entre ambos, por lo que los animales no requieren percibir ni comprender más allá de lo necesario para ese calce en cada instante. Por eso, si seguimos la noción de Umwelt, ni la abeja ni ningún animal comprenderán el pistilo en tanto tal, sino en la medida en que este es significativo para aquella, lo que no impide que calcen. Así, en la Sexta carta biológica, von Uexküll escribe:

En el mundo biológico todo es armonía, todo es melodía [alles Harmonie, alles Melodie]; porque los momentos en él no existen sólo para encadenar unos a otros los movimientos, sino que vienen a acentuar las sensaciones [...] Una fuerza superior al espacio y al tiempo sustenta, mueve y forma todo: la coordinación biológica [Planmäßigkeit] (von Uexküll, 1920: 66) ${ }^{2}$.

En la séptima carta se lee: "no hay evolución [Entwicklung]; sólo hay origen [Entstehung]" (76); "llenar plenamente el puesto que en el mundo le corresponde al animal es el fin de toda morfogénesis" (84), pues la adaptación sería un rasgo activo que hace coincidir al sujeto con el mundo circundante [Umwelt] (84); y en la página siguiente: "La coordinación biológica [Planmäßigkeit] es la fuerza cósmica que crea los sujetos" (85) (Die Planmäßigkeit ist die Weltmacht, die Subjekte schafft" (1920, p. $75)$. Aun más, en la carta octava sostiene que a cada propiedad de una especie viviente

2 Todas las traducciones de von Uexküll y posteriormente todas las que provienen del francés son nuestras. 
corresponde otra de su mundo circundante (87). En la línea de von Uexküll, Heidegger entiende que los animales solo se adaptan en la ontogénesis a ese entorno, pero no toma en cuenta la adaptación filogenética, transformando la Umwelt en un destino cerrado y excluyendo toda hipótesis de coadaptación, de cambio por influencia recíproca en una historia evolutiva natural y/o social. Por cierto, podemos vislumbrar en ello algunas consecuencias biopolíticas: la necesidad de adaptación armónica de los individuos a la nación, la que somete a los individuos sin que aquella requiera de estos algún tipo de acuerdo social que conduzca a la adaptación recíproca, el corte tajante entre animales y humanos, y la incomprensión de lo que hoy se entiende por Umwelt. La noción contemporánea de medio ambiente supone la coevolución de las especies y del entorno biológico, geográfico y climático. Por ello mismo, muchas especies animales no solo no se restringen a vivir en una "pobreza" de mundo, sino que se relacionan con él de forma abierta y de la forma y riqueza que conviene a su vida. El aporte de von Uexküll es decisivo para la comprensión de la relación entre la sicología animal y el entorno, en especial para entender que es una relación significativa, pero la interpretación heideggeriana pone en acento en el "encaje" antievolucionista y califica de pobre a la percepción de la abeja (eliminando la riqueza significativa que para el individuo animal tiene lo sentido por este).

En consecuencia, el camino heideggeriano no permite comprender los hechos fundamentales de la diferencia antropo-zoológica. Lo animal no surge ni se define por la ausencia de las capacidades de conocimiento de un pistilo en cuanto tal ni tampoco de la capacidad de ideación/no ideación metafísica de la abeja; y la noción de pobreza y riqueza de mundo fallan por fundar su origen en una biología que supone el encaje perfecto, inmóvil y a-significativo de las especies en su medio ambiente; en resumen, se trata de una concepción que Burgat define como la de un mundo humano mutilado (2006, p. 121).

\section{La búsqueda de la diferencia antropológica}

A lo anterior debemos agregar que la relación con los animales no compete solo al ámbito de la biología, ni de la metafísica, ni es un asunto privado que pueda decidir un científico o un filósofo. En primer lugar, porque no parece que entre los humanos haya asuntos que sean exclusivamente privados, asuntos donde ninguna autoridad pueda inmiscuirse ni establecer normas; y, en segundo lugar, lo que aun es más importante, porque hablar de animales supone haber creado previamente una distinción entre distintos tipos de seres vivos, distinción que justamente los separa entre humanos y animales. En realidad, ambos aspectos se funden en uno solo: hablamos de animales y nos relacionamos con ellos porque previamente ha habido una decisión -tácita o explícita- de crear un criterio que separe a los humanos del resto de la naturaleza y, dentro de ella, de los animales. Para que una relación con los animales pueda ser motivo de reconocimiento o discusión es necesario que previamente haya sido concebida la distinción entre humanos y animales. Ahora bien, ¿dónde colocar esa distinción? Responder esta pregunta equivale a conocer el criterio y el momento en que una especie 
de seres vivos pueda ser considerada distinta de todas las demás. Esa conclusión no es solo científica o académica, sino que se relaciona con el hecho social del comportamiento humano hacia los otros seres vivos. La definición de animal, por un lado, coestablece la frontera y da contenido a lo que se considera humano y, por otro, se sitúa como el fundamento de legitimidad de cierto tipo de actos hacia otros grupos de seres vivos, humanos o no, de forma que involucra aspectos centrales de la supervivencia y del estilo de vida de los seres humanos. Ahora bien, aunque ambos aspectos, el epistemológico y el político se entremezclen hasta hacerse inseparables, lo que se llama animalidad es un fenómeno global relacionado con el ser humano y cualquier descripción que se intente de ello involucra al ser humano mismo, motivo por el que el tema va mucho más allá de una biología que pretenda describir desinteresadamente un fenómeno. Desde el punto de vista de la propia existencia humana, en la definición y descripción de lo animal, el ser humano se pone en juego. Ello por dos motivos. El primero: la definición de lo animal le concierne siempre y nunca se restringe a la definición de un objeto ajeno a la existencia y a la subsistencia humana, porque tampoco hay vida humana sin vínculo presente con la vida animal. Y, el segundo, desde el punto de vista epistemológico, en la medida en que animal y humano son conceptos fronterizos y que además el primero incluye al segundo, al describir al animal o al describir al ser humano, quien describe al otro está realizando también una descripción de sí, incluso antes de suponer algún tipo de relación política o de dominio entre ambos grupos de seres vivos. El involucramiento entre lo animal y lo humano es de carácter ontológico y epistemológico; la existencia del ser humano y la existencia del animal están unidas por el solo acontecimiento de vivir y existir; toda relación posterior tiene por base este hecho y es una de sus determinaciones, que puede complementarlo o incluso intentar anularlo o minusvalorarlo, pero no anularlo.

Ahora bien, una cosa es que podamos definir el involucramiento existencial del ser humano y del animal y otra es discutir cómo pudo haberse llegado a tener noción de que algo así como un animal era distinguible, condición previa para que los humanos hayan podido tomar conciencia de que se involucraban con seres vivos calificados como distintos de ellos. En efecto, el involucramiento biológico y existencial no implica que haya conciencia de ello en las partes involucradas ni tampoco que se esté en condiciones de establecer el criterio de por qué y cómo se está en condiciones de colocar, por un lado, una multitud de seres vivos, para declararlos animales, y, por otro, un conjunto diferente de seres vivos que serán llamados humanos; por ello, no basta el involucramiento para definir con qué se está involucrado. Ahora bien, desde ya, podemos adelantar que el lenguaje nos traiciona en esta discusión, porque la noción de una multitud supone que dicha multitud forma parte del mismo conjunto, de algo que la puede unificar, lo que requiere haber establecido previamente el criterio de clasificación. Del mismo modo, hablar de "humanidad" supone haberla incluido en un solo conjunto, lo que, como se sabe, ha sido numerosas veces cuestionado, como sucedió, en el mundo americano, con los indígenas, materia que resolvió -aunque entonces no siempre convenció- la iglesia católica con la bula Sublimis Deus de 1537 (Vaticano 1537). Que toda agrupación solo sea posible habiendo primero establecido el criterio de ella lo planteó Jorge Luis Borges en el cuento El idioma analítico de John Wilkins. 
Esas ambigüedades, redundancias y deficiencias recuerdan las que el doctor Franz Kuhn atribuye a cierta enciclopedia china que se titula Emporio celestial de conocimientos benévolos. En sus remotas páginas está escrito que los animales se dividen en (a) pertenecientes al Emperador, (b) embalsamados, (c) amaestrados, (d) lechones, (e) sirenas, (f) fabulosos, (g) perros sueltos, (h) incluidos en esta clasificación, (i) que se agitan como locos, (j) innumerables, (k) dibujados con un pincel finísimo de pelo de camello, (1) etcétera, (m) que acaban de romper el jarrón, (n) que de lejos parecen moscas (Borges 1981).

Falta allí, como es notorio, o al menos no lo hace explícito Borges, el criterio de la clasificación, lo que también llama la atención a la vez filosófica e hilarante de Foucault en el Prefacio de Les mots et les choses (Foucault 1988). Allí escribe que el orden clasificatorio es un sistema de elementos que define umbrales sobre los cuales pueden aparecer semejanzas y diferencias (11). En esa clasificación constatamos que, si estableciéramos la categoría de seres vivos "dibujados con un pincel finísimo", encontraríamos muchos individuos humanos y animales que podrían caer dentro del mismo conjunto, lo que paralelamente serviría de apoyo para regular la relación entre humanos y animales de un modo peculiar.

\section{Algunos criterios no empíricos de distinción}

Hechas estas consideraciones, tenemos el marco desde el cual examinar algunos trabajos relativos a la diferencia entre animales y humanos. Bimbenet busca una diferencia tajante entre ambas especies, una diferencia antropológica neta, pero que no sea de origen empírico (E. Bimbenet 2011). ¿Lo consigue? Veámoslo. Para alcanzar su objetivo revisa una parte de la literatura sobre el tema y distingue tres tipos de relatos contemporáneos sobre la humanización, es decir, tres tipos de relatos que clasifican al ser humano como una especie distinta de la de los animales. El primer relato sería el de la paleontología, de donde se puede extraer datos determinantes, como el hecho de que estamos en un proceso evolutivo que nos vio como animales antes de vernos como ser humano; que nos definimos como algo distinto de un animal (50); y que nada predisponía a los homínidos a llegar a la forma actual (51), es decir, la hominización no es un destino ni de la historia ni de la naturaleza, sino un hecho que bien pudo haber sido distinto. El segundo relato sería el de la antropología filosófica, especialmente fenomenológica, que ha definido al hombre como un lugar de falta y dotado de intencionalidad, pues el ser humano sería de alguna manera un ser incompleto; tal sería el caso de Heidegger, Gehlen, Plessner, Sloterdijk. Este relato se aproxima a algunos argumentos etológicos (64). El ser humano -según el comentario de Bimbenet sobre Sloterdijk-, solo se puede poner en ruta a partir de la protección de una "esfera" asegurando la repetición de prestaciones dadas previamente por el útero (71), dando cuenta con ello de la necesidad de protección y de un tipo de insuficiencia. Asimismo, para Bimbenet, el camino de Heidegger debiera ser hecho en sentido inverso: del ser humano al animal (116). El tercer relato sería el de la antropología estructural de Lévi-Strauss, que muestra el paso de la naturaleza a la cultura o del estado de naturaleza al social (Lévi-Srauss 1981 [1948]). 
Según Bimbenet, el punto de partida de Lévi-Strauss es el origen de la cultura, algo que la ciencia no habría podido resolver. Por ello, concluye Bimbenet: “el análisis de hecho hace indecidible la división de lo biológico y de lo social en el hombre. Nuestra humanidad debe representarse como una estructura de comportamiento que integra lo biológico en ella" (74). La investigación empírica no mostraría nada que nos pueda informar del paso de la naturaleza a la cultura, incluso si se ve en las generaciones de australopitecos que se fueron transformando en homo un indicio de técnica, de moral o política, pues lo que manifiestan es la pobreza de esas características. En consecuencia, para Lévi-Strauss, habría que "rendirse" al análisis "ideal” de Rousseau, lo que significa establecer una línea de partición. Para Lévi-Strauss, la prohibición del incesto sería el fenómeno humanizante, aquel que separa de lo animal y de lo natural; la sociedad no puede nada contra la procreación, pero mucho respecto de la alianza. Bimbenet sostiene que la antropología lévistraussiana es un proyecto sintético que consiste en saber qué del hombre es natural y qué cultural; durante esa primera etapa, la antropología es fundamental antes que estructural, pues se trata de establecer verdades generales que orientarán la investigación, orientación llevada a cabo por la experiencia del sujeto (Bimbenet 73). Sin embargo, a pesar de reconocer las dificultades de facto para practicar dicha distinción, Lévi-Strauss valorizaría su valor lógico y la justifica como instrumento de método (3).

Nos parece que la descripción hecha por Bimbenet de las tres grandes líneas de trabajo relativas al tema es ajustada, sin perjuicio, como veremos más adelante, de que no extraiga todas las consecuencias que de ello se imponen. De momento, es conveniente recalcar que la distinción entre animales y humanos, como acabamos de ver en las tres áreas que aborda Bimbenet, se vincula con las etapas o pasos de la vida humana y también con lo que se ha llamado la diferencia entre una vida natural y otra cultural/social.

Para valorar la propuesta de Bimbenet es necesario seguir sus pasos, al menos parcialmente. Por ello analizamos con un poco más de detención cómo se aborda la transición de la animalidad a la humanidad desde una propuesta paleontológica. En un libro ya clásico de los antropólogos empíricos Washburn y Moore, titulado Del mono al hombre (Washburn and Moore 1986 [1980]), tras describir el descubrimiento de las primeras huellas humanas fosilizadas hace unos 3,6 millones de años, se narra el descubrimiento arqueológico de los primeros instrumentos. Ahora bien, el libro no decide si los australopitecos eran humanos por el solo hecho de que se haya podido probar que hayan usado instrumentos. El solo uso de instrumentos por los australopitecos no basta a los autores para declarar que allí se da el momento temporal en que comienza la humanidad. Para resolver ese enigma, los autores consideran necesario hacer uso de una batería más amplia de datos, como los provenientes de la biología molecular (ADN, proteínas, inmunología, electrofóresis) y de la morfología (estudio del tronco, extremidades, cráneo) (Washburn and Moore 1986 [1980], pp. 27-32). Gracias a ello, proponen un esquema donde colocan, aproximadamente, a los antropoides hace 20 millones de años y a los australopitecos hace 5 millones (156), pero distinguen en estos últimos al Homo erectus ( 0,5 millones de años), al Neanderthal ( 0,1 millones de años) y al Homo sapiens (0,04 millones de años), para concluir que: 
algunos antropoides primitivos evolucionaron lentamente y poco a poco hasta convertirse en australopitecinos, seres en parte humanos y en parte antropoides que fundaron la linea evolutiva humana (79).

En otras palabras, los autores no se deciden por un criterio único de diferencia, pero enuncian una serie de cualidades: posición erecta, marcha bípeda constante, herramientas, lenguaje, sin que, sin embargo, puedan, por ejemplo, establecer cuál es el porcentaje de la marcha bípeda exigida para hablar de ser humano en relación con la marcha alternada (bípeda y cuadrúpeda) de algunos simios contemporáneos. La expresión lentamente y poco a poco hasta convertirse en australopitecinos, seres en parte humanos y en parte antropoides que fundaron la linea evolutiva humana muestra que en sí no son los grandes fenómenos morfológicos, de percepción o ideación lo que transforma a los australopitecinos en seres humanos, sino que el valor diferencial está dado por un conjunto de criterios cuya comprobación se constata después por medio de la observación de una continuidad. Así lo demuestra también la confusión generada por el caso del llamado hombre de Naladi. Lee Berger, el jefe de la excavación de la cueva Rising Star, declara que el hombre de Naladi no es humano, pero poco después entra en matizaciones que más bien muestran lo contrario o mucha ambigüedad. Para él, el hombre de Naladi "es un animal que parece tener la capacidad cognitiva para reconocer su separación de la naturaleza", y después afirma que tiene rasgos mixtos en el mismo cuerpo, de australopiteco y de homo habilis, pero con comportamientos funerarios que son propios de este último e incluso del homo sapiens, lo que coincide, una vez más, con la imposibilidad de fundar empíricamente la distinción entre hombre y animal (Shreeve 2015). Berger se expresa de este modo: primero declara la animalidad del hombre de Naladi para desmentirla casi inmediatamente, pues los ritos funerarios corresponden exclusivamente al género homo, y no a un "animal" de talla pequeña, morfología a la vez simiesca en algunos aspectos y humanoide en otros, y de un cerebro de apenas $500 \mathrm{~cm}$ cúbicos. La tarea de la clasificación y de la distinción es justamente la de generar la regla que permita distinguir allí donde hay un continuo entre seres vivos.

Siguiendo el examen que hace Bimbenet de algunos autores, veamos ahora el tercer relato sobre la humanidad: el de la antropología estructural por medio de Lévi-Strauss y de su fuente de inspiración: Rousseau, pero siguiéndolo de acuerdo con nuestro propio criterio. (El caso de Heidegger ya lo hemos examinado). Para Lévi-Strauss, el origen de la vida cultural o social se liga al relato sobre la animalidad, porque se subentiende que el ser humano dejó de ser simplemente un animal al mismo tiempo que adquirió una vida cultural. Ahora bien, incluso si aceptamos, con Lévi-Strauss, que conocemos el criterio de partición entre animales y humanos -que para él es la prohibición del incesto-, no sabemos cuándo se produce ese hecho, cuándo comenzó el ser humano a ser lo que es. Del "cuándo" temporal nos da una idea la paleontología, pero esta ciencia no logra hacerlo sin haber resuelto antes algunos temas que sí abordan Rousseau y Lévi-Strauss. En efecto, Lévi-Strauss concluye que es imposible referirse a un estado de la evolución del hombre en la cual no haya formas de actividad que no sean parte de la cultura (1981 [1948], 4). Lévi-Strauss reconoce que la distinción, incluso de método, entre lo cultural y lo natural, entre lo humano y lo animal, puede transformar en misterio el paso de la naturaleza a la cultura: si se rechaza la distinción de método, 
se niega la oposición de naturaleza y cultura, lo que sería negarse a comprender los fenómenos sociales, pues la noción misma de fenómeno social supondría tal distinción, lo que no impide que la distinción entre cultura y naturaleza sea difícil y que la cultura sustituya la vida natural más que agregarse a ella (Lévi-Strauss, 4). El establecimiento de la cultura y, en consecuencia, de la sociedad, coincide para Lévi-Strauss con el nacimiento de reglas matrimoniales o con su contracara, la prohibición del incesto, que no dependen de la biología, ni de la voluntad individual, sino de decisiones sociales.

Rousseau y Lévi-Strauss proponen un método que se aproxima a resolver lo que empíricamente carece de solución. En cambio, a pesar del esfuerzo por trabajar con datos y concluir a partir de ellos, Washburn y Moore y Berger dejan abierto un aspecto fundamental: ¿en qué criterio basar la distinción entre antropoides (de hace unos 20 millones de años) y los homínidos (de hace unos cinco millones) y, posteriormente, dentro de la especie homo, distinguir al homo habilis (2,4 millones de años), homo erectus ( 0,5 millones de años), de homo neanderthalensis ( 0,1 millones de años) y a este del homo sapiens (0,04 millones de años)? De los analísis culturales, morfológicos y de biología molecular, el resultado es que "algunos antropoides primitivos evolucionaron lentamente y poco a poco hasta convertirse en australopitecinos, seres en parte humanos y en parte antropoides" (p. 79). ¿Qué podemos concluir? Que los restos paleontológicos muestran una evolución lenta y continuidad, la que se rompe por la coincidencia, en determinado momento, por pequeños saltos de rasgos morfológicos y características genéticas. ¿Pero por qué esas características y no otras? ¿Por qué esos atributos son asignados al género homo? ¿Quién tiene la autoridad para asignarlos? En las descripciones precedentes, la humanización no tiene como criterio un hecho biológico (aunque, como hemos visto, pueda requerirlo), ni tampoco el solo hecho de vivir en sociedades, ni producir artefactos. En realidad, lo que se constata es que distintos autores adhieren a una decisión epistemológica que establece una separación, aceptada por la comunidad científica, para distinguir entre animales y humanos dentro de un continuo biológico, tal como hace Berger, en medio de su confusión, cuando del hecho de que el hombre de Naladi tenga comportamientos funerarios ya no está seguro de si éste era el animal que se deduciría de su morfología. Lo que se observa en las huellas paleontológicas es proximidad morfológica, una diferencia apenas de grado en capacidades intelectuales o sensibles, la estructuración de la vida en sociedades con sistema de colaboración y jerarquía, proximidad genética y otras cualidades comunes hasta que convencionalmente se establece que tal o cual característica es propiamente humana. Sucede, en cuanto a la diferencia antropológica, que el umbral de diferencia no está dado por las condiciones empíricas, sino por el contenido y fineza de la distinción epistemológica.

Es por eso que conviene recordar la propuesta hecha por Rousseau, quien se enfrentó a un problema estructuralmente semejante: ¿cómo distinguir entre el ser humano en estado natural y el ser humano en condición social? No en vano, tanto Lévi-Strauss como Bimbenet se refieren a él. En el Discours sur l'origine de l'inégalité parmi les hommes (1970 [1755]), Rousseau distingue entre el hombre en estado natural y el hombre en estado social, pero no se pronuncia por el momento exacto en que una evolución o una ruptura se habría producido, dando lugar al abandono de la vida natural y al inicio de la vida social. Es más, Rousseau descarta los hechos históricos al tratar el tema, 
pues hace uso de lo que él llama un razonamiento hipotético destinado "a esclarecer la naturaleza de las cosas" y no a definir el cuándo temporal de dichas "cosas" (45). Siguiendo ese razonamiento hipotético, en el caso de Rousseau, la diferencia entre el estado de naturaleza y el estado social está dada por la existencia de la propiedad. Rousseau percibió que la propiedad no es solo un objeto, sino un derecho ejercido sobre dicho objeto, derecho que permite el acceso en exclusiva de una persona a ese bien, restringiendo el acceso a las demás personas. Que ello sea así no depende de una declaración unilateral, sino sobre todo de la aceptación social o incluso la protección social de esa restricción de acceso a los objetos considerados propiedad: "el primero que cercó un terreno y tuvo la idea de decir esto es mío y que encontró gente lo suficientemente simple como para creerle fue el verdadero fundador de la sociedad civil" (Discours sur l'origine de l'inégalité 1970 [1755]), 165). Nótese que Rousseau aclara que no basta con decir esto es mío; esa parte de la oración carecería de sentido si no estuviese acompañada por la segunda parte, que es y encontró gente lo suficientemente simple como para creerle; la propiedad no se constituye únicamente, entonces, por el hecho de que alguien la reclame, sino porque los demás acepten la reclamación. Es la aceptación por terceros, y no la reclamación por sí misma, lo que la valida y valida la clasificación y separación de los objetos entre aquellos que son y no son propiedad. La aceptación por terceros es un reconocimiento colectivo que confirma el propósito de buscar ser propietario para distinguir un bien propio en relación con otros bienes comunes; sin la validación social, el reclamo del aspirante a propiedad es nulo. La propiedad separa y distingue, dentro del conjunto de objetos, aquellos que son de uso y disfrute exclusivo respecto de aquellos que no cumplen dicha característica. Ahora bien: ¿la característica de uso exclusivo, disfrute e incluso derecho de destrucción, como se suele atribuir al derecho de propiedad, es una característica del objeto o es una norma de comportamiento humano? La propiedad no es una característica del objeto, sino un fenómeno de síntesis, porque asocia indisolublemente un acto social con un objeto; el derecho de propiedad, en la teoría roussoniana, no podría ejercerse ni establecerse sobre un bien inexistente, pero el solo hecho de que exista un bien no lo transforma en propiedad; el derecho de propiedad es una aspiración legitimada, consentida y protegida por la sociedad. De acuerdo con Rousseau, podemos interpretar que la propiedad es un sistema de clasificación reconocido comunitariamente para distinguir cierto tipo de objetos y la relación de los seres humanos con estos y no una distinción natural entre los distintos tipos de bienes, permitiendo así un ordenamiento, entre muchos otros, para guiar las acciones humanas con los objetos de la naturaleza cuando estos suscitan el interés de otras personas ${ }^{3}$.

La respuesta roussoniana no requiere un estudio empírico, sino que se apoya en la existencia de una norma aceptada socialmente, la que establece la propiedad. Es a partir de la elevación de la norma social a criterio de humanización que la investigación

Es el punto que lo diferencia de la concepción de Locke sobre la propiedad, según la define en el capítulo 5 del Segundo tratado sobre el gobierno civil, donde la declara de origen natural y no consensual (Locke 1978). 
de Rousseau comienza a tener una dirección que permita discriminar la vida natural de la cultural, la vida prehomínea de la homínea. El procedimiento es el siguiente; en Rousseau: $1^{\circ}$ se constata empíricamente que no hay ninguna característica de los objetos ni tampoco del ser humano que de por sí impida ese acceso al conjunto de los objetos; $2^{\circ}$ se constata la existencia de una norma que restringe el acceso a ciertos bienes en beneficio de una sola persona; $3^{\circ}$ se constata que una comunidad da su asentimiento a esa norma (aunque no siempre la respete); y $4^{\circ}$ se define que la vida social se inicia justamente con la propiedad, es decir, con la constitución de la norma que prohíbe el acceso a bienes que han sido vinculados socialmente con terceros, aun cuando sean físicamente accesibles.

De modo semejante, en el caso de Lévi-Strauss, la característica que permite distinguir a los humanos de otros seres vivos es: $1^{\circ}$ se constata que biológicamente no hay nada que impida el acceso sexual a todas las personas de una comunidad; $2^{\circ}$ se constata que en esa comunidad existe una norma que restringe el acceso a ciertos miembros de ese grupo en beneficio de una persona; $3^{\circ}$ se constata que la comunidad da su asentimiento a la norma (aunque no siempre la respete); y $4^{\circ}$ se define que la vida social propiamente humana se inicia con la regla de parentesco, es decir, con la constitución de la norma que en la comunidad prohíbe el acceso a miembros de otro sexo que han sido clasificados como una subsección de la comunidad, es decir, con los parientes, aun cuando no hay nada biológico que impida su acceso sexual. En ambos autores, el punto de partida es el establecimiento de la norma por parte de una sociedad; en ambos autores, se trata de una regla universal.

Las reglas de paso del estado de naturaleza al social, cuyas características no son históricas sino una suposición metodológica, tal como advertía Rousseau, permiten comprender la existencia de un humano. Sin la definición de las reglas de la humanidad, lo humano es un sinsentido filosófico, un no-concepto, y, del mismo modo, también lo sería el animal. En ambos casos, si previamente no se han establecido las reglas para definir tales conceptos y no han sido aceptadas o bien socialmente o bien por una comunidad de especialistas, no podemos hablar ni de humanos ni de animales. Sin la conciencia humana de la animalidad, que ha tomado la forma de un colocarse fuera de esta, no existe el ser humano, porque el ser humano está definido, a la vez, por una norma o un conjunto de normas y por el hecho de ser socialmente consciente de ellas. Estas normas no requieren una definición teórica, pero suele haberla, en especial en las comunidades científicas, pero para la mayor parte de la población son más bien reglas de comportamiento aceptadas o prohibidas hacia grupos de ser vivos. En la medida en que los mismos humanos las establecen, les sirven para concebirse como especie diferente respecto de los humanos en estado natural (en el caso de Rousseau) o para distinguir la vida social de los humanos de la existencia de los animales (en el caso de Lévi-Strauss). La transgresión de la norma no la anula, como el robo no anula la propiedad, como tampoco la unión sexual entre parientes anula la prohibición del incesto, sino que el robo existe porque existe la propiedad y el incesto existe porque se establece una prohibición de acceso sexual a ciertos parientes. No solo no corresponde castigo cuando no hay ley que defina la transgresión, según el antiguo proverbio latino, sino que tampoco hay delito sin la norma que lo establezca, como expresa el 
artículo tercero de la Constitución de la República de Chile y la de muchos otros países occidentales: "Ninguna ley podrá establecer penas sin que la conducta que se sanciona esté expresamente descrita en ella" (República de Chile 2005). El reflejo ético-político de ello es que solo se podrá hablar de transgresión de comportamientos debidos hacia una especie, por ejemplo hacia los animales, si previamente hay una regla que permita distinguir a dicha especie de la nuestra y, al mismo tiempo que la distingue, establezca lo debido y lo indebido para ella.

La diferencia entre propiedad y bienes comunes, entre naturaleza y cultura o entre animal y humano son hechos sociales y epistemológicos de los que inicialmente se tiene una conciencia no científica, pero que, si nos inspiramos en Rousseau y LéviStrauss, debemos aceptar como constituyentes de la humanidad en su estado actual. La naturaleza y los animales han acompañado a los humanos al menos a partir del momento en que estos concibieron la clasificación y el criterio de clasificación que distinguió a un grupo de seres vivos de otros. Solo entonces los humanos pudieron tematizar algo así como la cercanía o distancia entre ellos y los animales no humanos y se plantearon, quizás, qué tipo de relaciones se debía mantener con los demás seres vivos. Que previamente haya habido algún tipo de presencia y vínculo biológico es, más que probable, algo seguro, pues tanto filogenética como ontogenéticamente humanos y animales estamos vinculados. Lo que cambia al ser concebida la diferencia antropológica es que esa compañía y proximidad son identificadas como compañía y proximidad animal y que en torno a ellas se puede realizar una multitud de elaboraciones teóricas, religiosas o míticas. Gracias al surgimiento de la condición epistemológica que diferencia a humanos y animales se da la posibilidad histórica de que una relación con los animales, como especie similar/diferente, sea puesta como tema, como objeto de una práctica filosófica u otra. Desde que existe esa clasificación, un niño nacido en una cultura capaz de distinguir entre humanos y animales tiene información sobre la existencia de los animales y adquiere la conciencia confusa, pero intensa, del parentesco y de la diferencia (los dos hechos al mismo tiempo) con ellos, no por un descubrimiento personal, sino por aprendizaje de un saber suprapersonal, que llega a parecerle natural y atribuible a una propiedad de las cosas por haber nacido dentro de ese saber.

La pregunta, entonces, por el comienzo de nuestro vínculo con los animales, debe ser transformada o al menos acompañada por la pregunta sobre el origen de la clasificación de ambos grupos de seres vivos. Y la respuesta es: la humanidad, antes de que lo concibiera y quizás antes de que se concibiera como humanidad, no reconoció vínculo con los animales porque entonces no existía el principio de clasificación que permitiera establecer algo así como una humanidad. El vínculo con los animales, entendidos como una especie distinta, solo surge junto con el percibir una diferencia dentro de la proximidad con otras especies y se identifica con la noción misma de humanidad que genera la regla de percepción. Una humanidad-como la concebimos hoy- que no mantenga relaciones con animales en tanto miembros de otra especie es impensable, cualquiera sea el momento, el lugar y el método (empírico, fenomenológico, filosófico) donde ello se dé, porque solo entendemos lo humano junto con esa diferencia. La existencia de una diferencia antropológica es circular: la diferencia encontrada y que permite colocar unos seres vivos dentro de un subconjunto aparte del de los 
humanos coincide con la diferencia puesta por la clasificación para, con ella, separar a unos seres vivos de otros.

Quizás haya otras especies animales que también se reconozcan como distintas de todas las demás y que tengan algún tipo de noción de ello. Tal vez, pero no corresponde aquí definir si las capacidades recién enunciadas son exclusivas del ser humano o si se extienden a las especies dotadas de sensibilidad. Esa vía ha sido ya suficientemente explorada por medio de una antigua y recurrente polémica sobre la capacidad de algunos animales de usar instrumentos, de identificar números, de memorizar información, de reconocer un pistilo en cuanto tal y otros comportamientos. Lo que es necesario enunciar es que humanos y animales son diferentes y que la noción de humano es fruto de una decisión epistemológica que lo distingue del animal y que solo entonces es posible la constatación empírica de ello; la diferencia es reconocible solo tras ser puesta. Tal distinción no podría tener por fundamento una característica de las cosas. Por eso mismo, sería una petición de principio buscar las diferencias cuando ya han sido establecidas en el concepto; los esfuerzos por buscar la diferencia específica analizando características morfológicas, de percepción, de ideación, de moralidad u otras solo confirman la decisión epistemológica previa de haber fijado una diferencia y constituyen una forma singular de tautología.

\section{La atención conjunta: la ambigua propuesta de Bimbenet}

La pregunta por el paso del mono al hombre, que pretenden resolver Washburn y Moore, no tiene solución en el plano en que la plantean: morfología, biología molecular, uso de herramientas, etc., pues algunas de estas características también pueden estar ausentes o presentes en seres que son considerados animales o humanos. Que algunas de las diferencias empíricas entre especies de animales y humanos no son nítidas, no por la presencia o ausencia de dichas características, lo muestra Tom Regan en el primer y segundo capítulo de The case for animal rights (Regan 1983, 1-81). Que un grupo de seres vivos haya alcanzado la posibilidad biológica de poder distinguir clases de seres vivos es un hecho de la evolución del cerebro cuya universalidad contemporánea se debe quizás a que tuvo lugar antes de que los humanos dejaran África y se produjera su diáspora mundial. Por esa misma razón, previamente afirmamos que Bimbenet no extrae todas las consecuencias de su análisis sobre Lévi-Strauss, análisis cuya fineza, sin embargo, hay que recalcar. En efecto, Bimbenet busca un componente exclusivo del ser humano en el ámbito de la comunicación y de la percepción. Siguiendo a Michel Tomasello, propone que "la atención conjunta" (attention conjointe) es uno de los criterios de la hominización y de aceleramiento de ella, atención que no se daría en los animales ${ }^{4}$. La atención conjunta estaría definida por el hecho de que quien percibe,

$4 \quad$ "Il y aura attention conjointe lorsque, vers les neuf mois, l'enfant saura projeter en autrui son rapport instrumental au réel, sa capacité à viser un objectif à travers différents moyens” (345). 
en su misma percepción da espacio a otro punto de vista en el mundo (331), a otra percepción. Esa inclusión de otro punto de vista constituye, además, una capacidad comunicativa de la objetividad y un criterio para definir al hombre y distinguirlo del animal. La atención conjunta permite, de acuerdo con Bimbenet, la posibilidad de identificarse con el congénere y así fundar la cooperación, la imitación, la enseñanza y el lenguaje, de forma que la atención conjunta se relaciona con y anexa todos los comportamientos humanos (315). Distanciándose de algunas formas de antropología basada en la pretensión de que solo el hombre tiene conciencia de sí, sin relacionarse con la conciencia del congénere, Bimbenet sostiene que esta conciencia no sería una característica central del hombre (389). En cambio, el examen comparativo de las de la percepción animal y humana muestran que "ningún animal podría vivir más de una hora sin el reconocimiento de lo mismo en lo otro, sin la puesta en perspectiva de lo nuevo desde su propio punto de vista" (392).

Bimbenet pone el acento en algunos aspectos esenciales, como el hecho de que el concepto de humano queda mejor definido por un tipo de sociabilidad, capacidad de realizar enunciados veritativos y de objetividad. Sin embargo, resulta ambiguo a la hora de decidir si su distinción es fruto de una constatación empírica del tipo de conocimiento o si previamente establece como criterio epistemológico de distinción la percepción conjunta, en la hipótesis de una jerarquía cognoscitiva entre humanos y animales. Aproximándose a Tomasello, Bimbenet considera que la percepción conjunta se da solamente entre los humanos. Al apoyar Bimbenet su búsqueda de lo humano en una característica empírica de carácter intelectivo ya sea la capacidad de atención conjunta o de enunciar lo verdadero y lo falso, todo ello a partir de los resultados de Tomasello, olvida que este no consigue unanimidad en sus planteamientos antropológicos y que, lejos de ello, ha sido criticado por su suposición de una habilidad cognitiva innata en los humanos (Vanniarajan 2000: 136) y porque su planteamiento relativo a la capacidad prelingüística "no considera una parte significativa de los datos de los grandes simios cautivos" (Savage-Rumbaugh 2000, 926). Savage-Rambaug sostiene que hay amplia información de que también al menos la atención conjunta y el lenguaje creador de un mundo se da en algunos animales. Nosotros agregamos que, para que la atención pueda ser conjunta, es preciso que previamente se haya establecido a aquella como criterio de distinción entre especies. Es decir, si Bimbenet busca que la distinción por él enunciada sea de origen empírico. En otras palabras, Bimbenet quiere que la distinción sea encontrada, pero no examina si para ser encontrada el criterio del encuentro debe ser previamente puesto. Si, en lugar de ser una diferencia encontrada, es una distinción puesta, es decir, un criterio y no una constatación, hubiera sido necesario que Bimbenet lo exponga nítidamente. Nosotros pensamos que la explicitación plena de la tesis de Bimbenet debiera ser esta: la atención conjunta es un criterio que permite distinguir a los animales humanos de los animales no humanos pero, como todo criterio, es una elección del investigador. Si seguimos el criterio de la atención conjunta en sentido estricto para establecer la diferencia antropológica, tenemos que algunos de los seres vivos que hoy consideramos animales debieran ser considerados humanos, pues hay atención conjunta en algunos animales, como sostienen Savage y Rumbaugh, y algunos animales humanos debieran ser considerados simplemente animales. 
El punto no resuelto por Bimbenet es la naturaleza de la atención conjunta, ya sea como hecho encontrado o criterio puesto. $\mathrm{Y}$ es un punto central. En otras palabras, no es que la atención conjunta de la que se sirve Bimbenet sea inútil, por importantes que sean sus consecuencias, según acabamos de mencionar, sino que es necesario decidir si es un criterio o un hecho. Cualquiera que sea el camino que se escoja, pero más aún por la vía empírica, siempre se podrá encontrar individuos comúnmente clasificados en una especie animal que, reclasificados en sentido estricto, deben ser colocados en la especie vecina de los humanos.

Al no resolver este tema, se debilita uno de los principales puntos de apoyo de Bimbenet, lo que sería menos relevante si no buscara en el hecho de la exclusividad de atención conjunta el criterio para definir al hombre y distinguirlo del animal. La propuesta de Bimbenet es positiva, pero insuficiente, al no considerar que la atención conjunta no es fundante de la distinción, que no es la observación la que establece la diferencia, sino que ese concepto está ya fundado por una decisión en la cual y por la cual se le define y coloca como criterio de distinción. El mismo Bimbenet parece consciente de esos límites y suavizará su posición. Más adelante, en el mismo texto L'animal que je ne suis plus, agregará que empíricamente no hay una distinción clara entre humanos y animales. Se trataría solo de probabilidad, pues la atención conjunta no estaría exactamente ausente en los animales, aunque sí sería "improbable o estadísticamente rara" (improbable ou statistiquement rare) (323); y, del mismo modo, sería "si no imposible, al menos estadísticamente improbable" (335) encontrar en los animales un punto de vista constitutivamente social sobre los objetos o que transforme esencialmente las relaciones con las cosas y consigo mismo (335-6). Con ello, deshace una parte del camino adelantado y disminuye la fuerza de su búsqueda de un criterio, viéndose en una encrucijada similar a la del ya citado libro Del mono al hombre..., de Washburn y Ruth Moore, quienes, aunque por razones distintas, finalmente también han de contentarse con una diferencia poco a poco.

Las distinciones epistemológicas son indispensables para los seres vivos que necesitan orientar su acción e interacción, más aun en aquellas especies que a lo largo de la evolución han hecho de la multiplicidad de sus acciones, pero también de su diferenciación individual, un instrumento para relacionarse por medio del mundo mental con sus congéneres y para sobrevivir. Esta precisión puede incluir la capacidad de observación y contemplación sin un fin utilitario inmediato, lo que para Bimbenet es una característica específica de la humanidad. Dichas distinciones son coherentes con un conjunto de relaciones sociales, incluyendo las relaciones políticas. Así sucede, no solo con las diferentes clasificaciones hechas entre humanos y animales, sino también dentro de los grupos humanos, pues eso permite, una vez establecida la distinción entre animales y humanos, distinguir subunidades al interior de estos o de aquellos, lo que facilita establecer alianzas y oposiciones con subgrupos dentro de ellos y matizar, en consecuencia, las relaciones con los congéneres. Es necesario alejarse tanto de los criterios metafísicos o seudo metafísicos de diferencia antropológica como de los empíricos y retomar la escuela de Rousseau y Lévi-Strauss. Los conceptos de animal y de humano son de comprensión variable y esta es definida por una decisión epistemológica, no por constatación de hechos; es en su definición y no en los individuos que llenan y dan 
extensión al concepto de humano donde debe buscarse la diferencia. Lévi-Strauss lo resume en términos simples: "La especie es el operador que permite pasar (e incluso obliga) de la unidad de una multiplicidad a la diversidad de la unidad" (Lévi-Strauss 1962, 180). Podemos, entonces, responder a la pregunta inicial: no pueden resolverse las diferencias antropológicas en relación con los animales únicamente por constatación y se requiere previamente una decisión epistemológica que pone lo que después el observador encontrará.

\section{Referencias bibliográficas}

Agamben, Giorgio (2006), Lo abierto. El hombre y el animal. Buenos Aires: Adriana Hidalgo.

Aristote (1957), On the soul, Parva Naturalia, On Breath. Translated by W. S. Hett. Vol. VIII. London y Massachusetts: Harvard University Press.

Aristóteles. Aristote (2006), Part of animals. Movement of animal. Progression of animals. Vol. XII. Cambridge: Harvard University Press [1937].

Bimbenet, Etienne (2011), L'animal que je ne suis plus. París: Gallimard.

Borges, Jorge Luis (1981), Otras Inquisiciones. El idioma analítico de John Wilkins. Vol. 1, Obras Completas 1923-1972, de Jorge Luis Borges, 706-710. Buenos Aires: Emecé.

Burgat, Florence (2012), Une autre existence. París: Fayard. $311 \mathrm{pp}$.

(2006), Liberté et inquiétude de la vie animale. Paris: Éditions Kimé,

Condillac, Étienne Bonnot de (2010), Traité des animaux. 10 de octubre de 2012 [1755].http://philosophie.ac-creteil.fr/IMG/doc/Condillac_Traite_des_ animaux_orthographe_non_modernisee_doc abril 2012 (accessed 2010).

Derrida, Jacques (2006), L'animal que donc je suis . Edited by Galilée. París: Galilée.

Descartes, René (1983), Discours de la méthode; Méditations, objections et réponses; Las passons de l'âme; Traité de l'homme; Lettres. In Descartes. Oeuvres. Lettres. Colléction La Pléiade. Edited by André Bridoux. París: Gallimard.

Donaldson, Sue, and Will Kymlicka (2011), Zoopolis. A Political Theory of Animal Rights. Nueva York: Oxford University Press.

Fontenay, Elizabeth (1998), Le silence des bêtes. La philosophie a la épreuve de l'animalité. Paris: Fayard.

Foucault, Michel (1988), Les mots et les choses. Paris: Gallimard.

Gaffoglio, Loreley (2015), Diario La Nación, Buenos Aires. 7 de septiembre de 2014. http://www.lanacion.com.ar/1725226-personas-no-humanas-el-pedido-porlos-chimpances-que-analiza-la-justicia (accessed 12 de agosto de 2015).

Heidegger, Martin (1992), Grundbegriffe der Metaphysik. Welt - Endlichkeit Eiseimkeit. Gesamtausgabe. II. Abteilung Vorlesungen 1923-1944. Vol. 29/30. Frankfurt am Main: Vittorio Klosterman [1930]. 
(2012 ), Ser e tempo. Edited by Fausto Castilho. Petropolis: Editora Vozes - Editora Unicamp [1927].

Laercio, Diógenes (1999), Diógenes Larcio. Vida de los más ilustres filósofos griegos. Trad. José Ortiz y Sainz. Barcelona: Folio.

Lévi-Srauss, Claude (1981), Les structures élémenataires de la parenté. Paris: Mouton [1948].

Locke, John, (1978), Two Treatises of Government, Vol. 1. 1 vols. Londres: Everman's Library, 1978 [1622].

Regan, Tom (1983), The Case For Animal Rights. San Francisco: University of California Press.

República de Chile (1980), "Constitutución Política (1980)”. Biblioteca del Congreso Nacional. 2005. http://bcn.cl/4r4m (accessed 13 de noviembre de 2012).

Rousseau, Jean Jacques (1970), Discours sur l'origine et les fondements de l'inégalité parmi les hommes. Vol. III, in J. J. Rousseau. Oeuvres complètes. Du contrat social. Écrits politiques, by Jean Jacques Rousseau, edited by B. \& Raymon, M. (Ed.). Gagnebin. París: Gallimard [1755].

Savage-Rumbaugh, Sue E. (2000), American Anthropologist, (American Anthopological Associatioin) 102, no. 4 (Diciembre 2000): 925-926.

Shreeve, Jamie (2015), “This Face Changes the Human Story. But How?" The National Geographic. septiembre de 2015. http://news.nationalgeographic. com/2015/09/150910-human-evolution-change/ (acceso el 20 de octubre de 2016).

Singer, Peter (1991), Animal Liberation. New York: Avon Books.

Vanniarajan, Swathi (2000), "The cultural Origins of Human Cognition". Issues in Applied Linguistics (University of California Press) 11, no. 1 (2000): 133-136.

von Uexküll, Jakob (1920), Biologische Briefe an eine Dame. Berlín: Gebrüder Paetel.

Washburn, S. L., and Ruth Moore (1986), Del mono al hombre. Un estudio sobre la evolución humana. Madrid: Alianza Editorial [1980]. 